\title{
Skin Hypopigmentation
}

National Cancer Institute

\section{Source}

National Cancer Institute. Skin Hypopigmentation. NCI Thesaurus. Code C78610.

Abnormal lightening of skin due to decreased melanin production or deposition. Vitiligo,

albinism, and leukoderma are among the disorders that are associated with skin

hypopigmentation. 